\title{
INTERNACIONALIZAÇÃO DA EDUCAÇÃO SUPERIOR E AVALIAÇÃO DA QUALIDADE DA PÓS-GRADUAÇÁO: RISCOS E PERSPECTIVAS NO Brasil e No ReINo UNIDO
}

\author{
INTERNATIONALIZATION OF HIGHER EDUCATION AND \\ QUALITY ASSESSMENT IN POSTGRADUATE STUDIES: RISKS AND \\ PERSPECTIVES IN BRAZIL AND THE UNITED KINGDOM
}

\author{
Mário Luiz Neves de Azevedo \\ Professor Titular da Universidade Estadual de Maringá (UEM) \\ Doutor em Educação pela USP (Faculdade de Educaçâo da Uni- \\ versidade de São Paulo), Pesquisador do CNPq. \\ ORCID: http://orcid.org/0000-0003-0563-5817.
} mlnazevedo@uem.br

João Ferreira de Oliveira Doutor e pós-doutor em Educaçáo pela Universidade de São Paulo (USP), Professor Titular da Universidade Federal de Goiás (UFG). Universidade Federal de Goiás. Brasil ORCID: https://orcid.org/0000-0002-4135-6340 joao.jferreira@gmail.com

\begin{abstract}
Resumo: Neste texto, analisamos o papel da CAPES na avaliação da pós-graduação (stricto sensu) e em sua política de internacionalização, considerando principalmente o Programa Institucional de Internacionalização (CAPES-PrInt), sem negligenciar elementos que indicam a existência de processo de mercadorização e transnacionalização da educação superior, com tendências de formação de um mercado global de educação superior. Para tanto, visando ilustrar essa discussão, trazemos alguns elementos desse processo no Brasil e no Reino Unido. Entendemos que há tensões e desafios que precisam ser considerados ao adotar a internacionalização como critério fundamental que distingue a qualidade e a excelência acadêmica na pós-graduaçáo stricto sensu, podendo implicar na conformaçáo de novos modelos de Pós-Graduação e na reestruturação do trabalho acadêmico.
\end{abstract}

Palavra-chave: Pós-graduação stricto sensu. Internacionalização da Educação Superior. Avaliação. CAPES. Educaçâo Superior no Reino Unido

Aвstract: In this paper, we analyze the role of CAPES in the quality assessment in postgraduate studies (stricto sensu) and its internationalization policy, considering mainly the Institutionalization Program of Internationalization (CAPES-PrInt), without 
neglecting elements that indicate the existence of a process of commodification and transnationalization of higher education, with trends for the formation of a global higher education market. To illustrate this discussion, we bring some elements of this process in Brazil and the United Kingdom. We understand that there are tensions and challenges that need to be considered when adopting internationalization as a fundamental criterion that distinguishes academic quality and excellence in stricto sensu postgraduate studies, as it may imply the shaping of new Postgraduate models and the restructuring of academic work.

KeYwords: Postgraduate studies. Internationalization of Higher Education. quality assessment. CAPES. UK University

\section{Introduçáo}

A Coordenaçáo de Aperfeiçoamento de Pessoal de Nível Superior (CAPES) foi criada em 1951 pelo Decreto no 29.741, tendo em vista "assegurar a existência de pessoal especializado em quantidade e qualidade suficientes para atender às necessidades dos empreendimentos públicos e privados que visam ao desenvolvimento do país"'. Nas linhas de atuação da CAPES fica evidente a ênfase no processo de internacionalização por meio dos investimentos na formação de recursos humanos de alto nível, na promoção da cooperação científica internacional, especialmente viabilizadas por intermédio de bolsas de estudo, e financiamento à pesquisa e a eventos, inclusive de natureza internacional, e na viabilizaçáo do acesso e divulgaçáo da produção científica nacional e internacional.

Uma das linhas fundamentais de atuação da CAPES é a avaliação da pós-graduação stricto sensu, que tem grande força modeladora nas diferentes áreas de conhecimento, dado que classifica os cursos/programas e que tem implicaçóes no maior ou menor volume de recursos direcionados aos mesmos para sua manutenção e desenvolvimento. É importante lembrar que o chamado "modelo CAPES de avaliação" foi criado e implementado a partir de 1976, em um contexto de institucionalização e expansão da pós-graduação stricto sensu, movimento iniciado a partir do Parecer no 977/1965, de Newton Sucupira, no âmbito do Conselho Federal de Educação, que objetivou implantar e desenvolver o regime de cursos-pósgraduaçáo no ensino superior brasileiro.

A política de pós-graduação contou ainda com um planejamento permanente por meio da elaboração, implementação e avaliação dos 
Planos Nacionais de Pós-graduação (PNPGs), sendo o primeiro instituído no período de 1975 a $1979^{2}$, o que certamente contribuiu para que a pósgraduação fosse assumida como política de estado, sendo garantida uma avaliação e supervisão permanentes, vinculadas a uma política de fomento, sobretudo de cursos/programas, marca distintiva da consolidação e expansão dessa etapa da educação superior no país.

A avaliação da pós-graduação stricto sensu, desde sua criação, via CAPES, vem sendo sempre modificada, tornando-se paulatinamente mais competitiva, discriminatória e distintiva dos cursos/programas, tendo em vista a lógica de melhorar a "qualidade" e elevar o "padrão de excelência acadêmica". Nessa direção, visando ampliar a "qualidade" e a "excelência acadêmica" vem ganhando relevo na avaliação da pós-graduação, especialmente a partir da segunda metade dos anos 1990, o critério da internacionalização, mediante a produção de artigos publicados em periódicos internacionais ou nacionais classificados como de padrão de internacional, ações acadêmicas conjuntas que resultem em produção intelectual, produção de patentes, bem como citações, índices e fatores de impacto, dentre outros. Os cursos/programas com conceitos/notas 6 e 7 , considerados de excelência e padrão internacional, são especialmente avaliados no tocante a internacionalização, cada vez mais considerando essas novas métricas ${ }^{3}$.

Neste texto, buscamos discutir e analisar o papel da CAPES na avaliação da pós-graduação stricto sensu e na política de financiamento à internacionalização, considerando principalmente o Programa CAPES-PrInt, mas sem negligenciar os elementos que indicam o processo em curso de mercadorização e transnacionalização da educação superior, com tendências de abertura do comércio de serviços educacionais e de formação de um mercado global de educação superior. Para tanto, visando ilustrar essa discussão, trazemos alguns elementos desse processo no Reino Unido e no Brasil. Entendemos que há tensóes e desafios que precisam ser considerados ao adotar a internacionalização como critério fundamental que distingue a qualidade e a excelência acadêmica na pós-graduação stricto sensu, dado o que isso significa efetivamente e o que pode trazer de implicaçóes para a modelação dos cursos/programas e para a produção do trabalho acadêmico. 


\section{A CAPES e o Programa Institucional de Internacionalizaçáo (CAPES-PrInt) em perspectiva}

A avaliação combinada com financiamento tem sido essencial para os avanços alcançados e deve seguir como pilar da evolução necessária do sistema, buscando maior autonomia, flexibilidade, integração entre áreas, aproximação com o ensino de graduação, a inovação e seus impactos nos setores não acadêmicos e empresariais na sociedade, a internacionalização e o reconhecimento da diversidade em suas múltiplas dimensões como elemento importante e norteador da pós-graduação no Brasil (BRASIL. CAPES, 2018, p. 23) ${ }^{4}$.

Analisar a qualidade da pós-graduação no Brasil relacionada à internacionalização pressupõe, antes de qualquer consideração, reconhecer a existência de um mega-ator que tem papel fulcral no Sistema Nacional de Pós-Graduação (SNPG): a CAPES. Por isto, não é ocioso lembrar que esta é uma estratégica agência de fomento para a expansão e consolidação da pós-graduação stricto sensu, produção e difusão científica e para a formação de professores da educação básica no Brasil, por intermédio da Diretoria de Formação de Professores da Educação Básica - DEB (BRASIL. CAPES, 27 AGOSTO 2018).

No campo da educação superior no Brasil, especificamente, em relação aos programas que formam pessoal em nível de mestrado e doutorado (stricto sensu), a CAPES desenvolve atividades amplas que regulam a pós-graduação por meio da avaliação, supervisão e financiamento dos programas de pós-graduação nas diferentes áreas de conhecimento, que estão distribuídos em 49 diferentes áreas de avaliação, formando o SNPG no Brasil.

O SNPG tem registrado forte crescimento das matrículas na pósgraduação stricto sensu, como se observa no período de 2015 a 2017 (Tabela 1). A expansão tem sido maior nas IES públicas, sobretudo nas universidades federais. Nas IES privadas a oferta é pouco significativa, com registro de pequena queda de 2015 para 2016, o que levou o governo de Michel Temer (2016-2018) a iniciar um processo de flexibilização da legislação para abertura e permanência de novos cursos/programas, inclusive a cria- 
ção, em 2017, de doutorados profissionais e a permissão de maior liberdade na oferta de cursos/programas na modalidade a distância, como evidencia a legislação do período (OLIVEIRA; LIMA, 2018).

\section{Tabela 1: Número de matrículas da Pós-graduação stricto sensu no período 2015 a 2017}

\begin{tabular}{c|c|c|c|c|c|c}
\hline \multirow{2}{*}{ Ano } & \multirow{2}{*}{ Total Geral } & \multicolumn{4}{|c}{ Categoria Administrativa } & \multirow{2}{*}{ Privada } \\
\cline { 3 - 6 } & & Total & Federal & Estadual & Municipal & \\
\hline 2015 & 325.230 & 269.395 & 184.041 & 83.856 & 1.498 & 55.835 \\
\hline 2016 & 347.035 & 292.023 & 200.442 & 89.937 & 1.644 & 55.012 \\
\hline 2017 & 361.530 & 304.146 & 210.305 & 92.217 & 1.624 & 57.384 \\
\hline$\Delta \% 2017 / 2015$ & $12,9 \%$ & $14,3 \%$ & $10,0 \%$ & $8,4 \%$ & $2,8 \%$ \\
\hline
\end{tabular}

Fonte: Elaboração própria a partir de dados dos Censos da educação superior do INEP.

Para o fomento da pós-graduação no Brasil, merecem destaque três modalidades de financiamento: o Programa de Apoio à Pós-Graduação (PROAP), o Programa de Excelência Acadêmica (PROEX) e o Programa Institucional de Internacionalização (CAPES-PrInt), sendo este último o programa destinado ao apoio à internacionalização da pós-graduação 5 . $\mathrm{O}$ PrInt foi lançado por intermédio do Edital no 41/2017, publicado em 07 de Novembro de 2017 e retificado em 02 de fevereiro de 2018, com os seguintes objetivos:

Fomentar a construção, a implementação e a consolidação de planos estratégicos de internacionalização das instituiçôes contempladas nas áreas do conhecimento por elas priorizadas; Estimular a formação de redes de pesquisas internacionais com vistas a aprimorar a qualidade da produção acadêmica vinculadas à pós-graduação; Ampliar as ações de apoio à internacionalização na pós-graduação das instituições contempladas; Promover a mobilidade de docentes e discentes, com ênfase em doutorandos, pós-doutorandos e docentes para o exterior e do exterior para o Brasil, vinculados a programas 
de pós-graduação stricto sensu com cooperação internacional; Fomentar a transformação das instituições participantes em um ambiente internacional; e Integrar outras açôes de fomento da Capes ao esforço de internacionalização (BRASIL. CAPES, 07 Nov 2017).

Mesmo sendo longa, a citação dos objetivos do CAPES-PrInt é uma forma de tentar compreender o sentido de internacionalização para a CAPES, pois, neste caso, é um rebatimento de sua regulação sobre o SNPG, inclusive no sentido de preservação e estímulo da qualidade na formação stricto sensu de pessoal e na produçáo do conhecimento, pois, no Brasil, "mais de $90 \%$ da produção científica nacional vem das universidades públicas, feita por professores e alunos de pós-graduação" (JORNAL DA USP, 28 Jun 2019).

A CAPES, por intermédio de seus editais e programas, sinaliza qual seu conceito de internacionalização e quais açôes de relaçóes internacionais são consideradas como pertinentes para catalisar a melhoria da qualidade na formação de pessoal e na produção científica. Nessa direção, entre as mais difundidas modalidades de internacionalização está a mobilidade transfronteiriça de estudantes e, também, de orientadores, que são, em grande medida, líderes de grupos de pesquisa consolidados cadastrados na plataforma do Conselho Nacional de Desenvolvimento Científico e Tecnológico (CNPq), outra fundamental agência federal de fomento à pesquisa e à inovação no Brasil ${ }^{6}$. De acordo com o INFOCAPES, "Em 2018, quase 10 mil estudantes obtiveram bolsas para o exterior, sendo que mais de quatro mil foram para doutorado-sanduíche" (BRASIL. CAPES, Dez 2018). No mesmo número do INFOCAPES, dedicado ao debate sobre internacionalização, Connie McManus, diretora de Relaçóes Internacionais da CAPES, adverte que

a internacionalização está forte em todas as universidades mundialmente. Se o Brasil não ficar atento a essa tendência, vamos perder muito espaço na ciência e na tecnologia. Ficaríamos isolados tecnologicamente, o que é muito ruim para as universidades e os pesquisadores (BRASIL. CAPES, Dez 2018). 
A propósito, em relação à avaliação dos Programas de Pós-Graduação, via sistema CAPES, a Comissão Nacional de Acompanhamento do PNPG, em relatório publicado em 2018, reconhece que o atual sistema avaliação da Pós-Graduação "atingiu um ponto de esgotamento e deve ser conceitual e objetivamente repensado e aprimorado" (BRASIL. CAPES, 2018, p. 3) e que novas demandas da comunidades acadêmica, cientifica, tecnológica e de inovação, sinalizam para necessidade da atualização dos procedimentos e critérios do modelo de avaliação. Demandas estas "relacionadas à consolidação, à internacionalização e à interação orgânica dos programas com setores não acadêmicos" (BRASIL. CAPES, 2018, p. 3).

Diante da necessária internacionalização da educação superior e, também, da produção do conhecimento, da inovação e da tecnologia, 109 Instituições de Educação Superior (IES) responderam ao Edital no 41/2017 CAPES-PrInt, enviando propostas com seus planos de internacionalização da pós-graduação para o concurso de um fundo de $\mathrm{R} \$ 300$ milhôes anuais, a serem aplicados no decorrer de 4 anos, ultrapassando a casa de $\mathrm{R} \$ 1$ bilhão (a previsão para o ano de 2018 era de $\mathrm{R} \$ 150$ milhóes) ${ }^{7}$. Podiam concorrer ao Edital PRINT-CAPES, as IES com ao menos quatro programas de pós-graduaçáo (pelo menos, dois cursos de doutorado) recomendados pela CAPES na última Avaliação Quadrienal 2017 (com notas não menos que quatro). Neste sentido, o British Council (2019), com base no edital CAPES-PrInt e em entrevistas, compilou os principais indicadores de avaliação para seleção das propostas de internacionalização das IES:

- Programas de pós-graduação com notas 5, 6 e 7;

- Qualidade da produção científica intelectual;

- Parcerias internacionais;

- Estrutura institucional;

- Viabilidade de execução da proposta;

- Atuação no Brasil e no exterior;

- Coerência entre tema, objetivos e açóes propostas para o projeto;

- Estratégias e políticas inovadoras;

- Relevância dos temas propostos e modelo institucional de gestão;

- Impacto da proposta para a internacionalização da instituição (BRITISH COUNCIL, 2019, p. 19). 
A CAPES publicou, em 01 de Outubro de 2018, o resultado da chamada PrInt. Apenas 36 Instituiçôes foram selecionadas, representando um complexo universo de 296 IES públicas (municipais, estaduais e federais) e 2.152 IES privadas, em que estáo registrados 8.290.911 estudantes de graduação e 361.530 de pós-graduação stricto sensu (mestrandos e doutorandos), segundo o Censo da Educação Superior de 2017, divulgado pelo INEP (BRASIL. MEC. INEP, 2018). A seleção de pouco mais de três dezenas de propostas no primeiro edital CAPES-PrInt oferece uma mostra da dimensão de internacionalização esperada, indicando um cenário de consolidação de núcleos de excelência já experimentados na internacionalização da educação superior.

Não por coincidência, as IES selecionadas no CAPES-PrInt são, justamente, aquelas que são sedes da maioria dos programas de pós-graduação com excelência certificada pelos conceitos/notas 6 e 7 reservados pela CAPES aos programas de pós-graduação avaliados como internacionalizados. Em entrevista publicada pelo British Council, Connie McManus, em resposta à questão "A intenção da Capes [com o PRINT] era, no primeiro momento, fortalecer as instituiçóes que já estão mais avançadas no processo de internacionalização?”, asseverou (e, em seguida, amenizou),

Exatamente. É uma questão de capacidade de implementação. Por isso foi decidido primeiro consolidar as que já têm condiçôes. De agora em diante, vamos verificar o que as demais precisam e ajudá-las. Vale lembrar que a Capes continua concedendo vários tipos de bolsas [sem grifos no original] (2019, p. 19).

As IES contempladas no CAPES-PrInt com financiamento para a internacionalização conquistam, por um período de quatro anos, uma fonte de sustentabilidade financeira para açóes de internacionalização, contemplando fundada preocupação da Comissão Nacional de Acompanhamento do PNPG que registrou em seu relatório que a internacionalização, na área de pós-graduação, "ainda é fomentada por programas governamentais descontínuos e que mudam de foco constantemente" (BRASIL. CAPES, 2018, p. 13). Cabe lembrar o CAPES-PrInt surgiu num contexto de crise econômica e social do Brasil, iniciado em 2013, e após o fim do Programa Ciências sem Fronteiras, que havia sido criado no 
governo de Dilma Rousseff (2011-2016). Buscou atender a demanda por financiamento à internacionalização, com maior autonomia das universidades, mas com um volume de recursos muito inferior ao que foi gasto no Programa Ciências sem Fronteiras.

Nesse contexto, como é sabido, a internacionalização da educação superior não é um fim em si mesmo (KNIGHT, 2011; DE WIT, 2013; AZEVEDO, 2014), especialmente porque o tesouro público, por intermédio de agências de fomento e universidades, são os financiadores e incentivadores de açóes de internacionalização. Logo, a expectativa que se cria com a internacionalização acadêmica é o cultivo do bem comum e o fortalecimento do bem público.

Por isto, a legítima e substantiva internacionalização é um processo intercultural de integraçáo de atividades de ensino, pesquisa e extensáo entre IES, inclusive seus programas de pós-graduação, por intermédio dos orgânicos atores acadêmicos que compóem suas respectivas comunidades universitárias. A internacionalização acadêmica se expressa por variadas formas de relacionamento, entre outras, por mobilidades transfronteiriças de estudantes, técnicos e professores, parcerias e convênios entre instituiçôes estrangeiras e a docência e a comunicação de resultados de pesquisa, nas modalidades presencial e a distância. Azevedo afirma que

a internacionalização da educação superior, potencialmente é processo e meio para a integração, a interculturalidade e o diálogo entre diferentes IES (nacionais e estrangeiras) e para a justa consecução do plano de desenvolvimento das universidades, logo de suas missóes precípuas, acordado pelas instâncias colegiadas acadêmicas, sob a proteção constitucional em cada país e estimuladas por políticas públicas que visam, ao mesmo tempo , à internacionalização solidária, às mudanças sociais e a integração regional (AZEVEDO, 2014, p.101-102).

Entretanto, ressalve-se que variadas ações que supostamente são classificadas como de internacionalização da educação superior podem, na realidade, ser de transnacionalização, reforçando-se tendências de abertura do comércio de serviços educacionais e de formação de um mercado global de educação superior (AZEVEDO, 27 Jul 2017). Por isto, sugere Azevedo, 
a prova de que se está fazendo internacionalização e não transnacionalização seria atentar se as açôes e as políticas de promoção da circulação internacional de ideias consideram os princípios de solidariedade, reciprocidade, interculturalidade, justiça social e respeito mútuo. Assim, sem querer fornecer uma receita, mas os atores sociais comprometidos com estes valores podem balizar suas açôes por estes princípios, procurando isentarem-se de carrear esforços para a formação de um mercado mundializado ou transnacionalizado de ensino superior, em que a competiçáo, os rankings e a educação como mercadoria tornem-se preponderantes (AZEVEDO, 27 Jul 2017).

\section{Uma breve reflexão sobre a mercadorização da educação superior no Reino Unido}

A Educação Superior no Reino Unido ${ }^{8}$, inclusive a pós-graduação, tem sido uma referência de políticas de internacionalização (transnacionalização?), de avaliação qualidade e de reformas para outros países, inclusive em relação a autonomia e financiamento. Ademais, são importantes atores políticos na promoção da educação superior do Reino Unido, agências e fundaçôes como British Council, que é um dos gestores do International English Language Testing System (IELTS); Newton Fund, organização britânica para ajuda ao desenvolvimento no campo da C, T\& I de países terceiros; e United Kingdom Research and Innovation (UKRI), que é uma organização semi-pública do Reino Unido de financiamento de pesquisa e inovação. A UKRI incorporou, a partir de sua criação em 01 de abril de 2018, o Higher Education Funding Council for England (HEFCE).

Estas organizaçóes e agências, ressalte-se, são atores sociais significativos para a promoção de seus sistemas de educação (básica e superior), ciência, inovação e da língua inglesa como língua franca acadêmica. De forma que as políticas públicas, a exemplo de políticas de internacionalização/transnacioalização (centrado na língua inglesa), financiamento (com mercadorização) e avaliaçáo da qualidade (performativa) adotadas no Reino Unido, muitas vezes, inspiram (por tradução) governos de outros países. 
O ponto de inflexão para o tratamento da educação como uma mercadoria no Reino Unido é desencadeado com a divulgação do Dearing Report ${ }^{9}$, em 1997. A publicação do Rapport Attali, em 1998, que recomendava a formação de um espaço de educação superior integrado na Europa, e o Processo de Bolonha, iniciado em 1999, que tinha por objetivo a estruturação de Espaço Europeu de Educação Superior (EEES), ampliam a atratividade das universidades britânicas e catalisam a mercadorização da educação superior, especialmente, na Inglaterra.

A propósito, Azevedo (2008) observou que o modelo inglês de educação superior foi tomado como o tipo ideal pela Comissão Pour un modèle européen d'enseignement supérieur, presidida por Jacques Attali (1998), que sugeriu a fórmula 3/5/8 ou LMD $(3+2+3)$, ou seja, a formação em nível superior com duração de três anos para a graduação (L de Licenciatura), dois anos para o mestrado (M) e três anos para o doutorado (D). O relatório foi recebido e aprovado por Claude Allègre, então Ministro francês da Educação Nacional, Pesquisa e Tecnologia (1997-2000), durante o governo de Lionel Jospin (1997-2002). O Rapport Attali, que propunha a integração europeia dos campos de educação superior, foi pauta da reuniáo, a convite do Ministro Allègre, de comemoração do $800^{\circ}$ aniversário da Universidade de Paris. Estiveram presentes os ministros da Educação da França (Claude Allègre), Alemanha (Jürgen Rüttgers), Itália (Luigi Berlinguer) e Reino Unido (Baroness Blackstone), que assinaram a "Declaraçáo de Sorbonne", lançando os fundamentos do Processo de Bolonha, iniciado no ano seguinte (1999).

Como é sabido, o Processo de Bolonha é o conjunto dos eventos relativos ao projeto de integração da educação superior a partir de princípios aprovados por ministros de educação de 29 países europeus em reunião, na cidade de Bolonha, em 1999. A denominação "Processo de Bolonha" é uma homenagem à primeira universidade criada na Europa no ano de 1088. Trata-se de um movimento de reformas visando à integração e regionalização europeia da educação superior. Para isto os ministros da educação dos 29 países europeus consignaram objetivos que encetavam a atratividade, o incremento da mobilidade acadêmica, a competitividade, a europeização da educação superior. Para isso, buscou-se a harmonização dos sistemas, de modo a equiparar os graus, diplomas, títulos universitários e currículos acadêmicos, e adoção de programas de formação que pos- 
sam ser reconhecidos e aceitos pelas autoridades nacionais comprometidas na Formação do EEES (AZEVEDO, 2010).

O EEES, conforme os objetivos do Processo de Bolonha, conta com a participação de IES de 48 diferentes países. Sem contar as reuniōes de seguimento e de outros grupos de trabalho, o Processo de Bolonha somou 10 reunióes ministeriais no período de 1999 a 2018 (para além, da reuniấo de Sorbonne, em 25 de maio de 1998). Faz parte do cronograma, a Conferência Ministerial para a promoção EEES de Roma, que deve ocorrer de 23 a 25 de Junho de 2020.

Com a finalidade de ilustrar, segue a lista das conferências ministeriais do Processo de Bolonha (EHEA, 31 Jul 2019):

1. Conferência Ministerial em Paris, 24-25 de maio de 2018.

2. Conferência Ministerial em Yerevan, 14-15 de maio de 2015.

3. Conferência Ministerial em Bucareste, 26-27 de abril de 2012.

4. Conferência Ministerial em Budapeste / Viena, 10 a 12 de Março de 2010.

5. Conferência Ministerial em Leuven / Louvain-la-Neuve, 28-29 de abril de 2009.

6. Conferência Ministerial em Londres, 17-18 de maio de 2007.

7. Conferência Ministerial em Bergen, 19 a 20 de maio de 2005.

8. Conferência Ministerial em Berlim, 18-19 de setembro de 2003.

9. Conferência Ministerial em Praga, de 18 a 19 de maio de 2001.

10. Conferência Ministerial em Bolonha, 18-19 de junho de 1999.

Vale ressaltar que o Processo de Bolonha, com vistas à formação do EEES, consagrou o sistema de créditos ECTS (European Credits Transfer Sistem). O ECTS, fundamental para a integração acadêmica regional, é um sistema de equivalência e de reconhecimento dos estudos realizados pelos alunos dos países europeus, tornado uma realidade por intermédio do programa europeu de intercâmbio de estudantes universitários Erasmus (acrônimo em inglês para European Region Action Scheme for the Mobility of University Students ou, em Português, Plano de Ação da Comunidade Europeia para a Mobilidade de Estudantes Universitários) ${ }^{10}$. $\mathrm{O}$ atualmente denominado Erasmus +, em 30 anos de existência, foi experimentado por 
mais de 9 milhões de pessoas, dessas 4,4 milhôes de estudantes de educação superior (EUROPEAN COMISSION, 31 Jul 2019).

Neste sentido, o Processo de Bolonha e a consequente formação do EEES contribuiu, especialmente, para a centralidade da educação superior do Reino Unido, pois houve uma tácita convergência dos campos europeus de educação superior ao modelo adotado de organizaçáo acadêmica vigente no Reino Unido, mais exatamente, na Inglaterra, acelerando a tendência de consolidação do inglês como língua franca para a comunicação no meio intercultural acadêmico na Europa. Aliás, o campo universitário global há tempo vem sendo hegemonizado pelos países de língua inglesa. Altbach (2006, p. 125-126) observa que

os mais importantes periódicos e banco de dados estão sediados nas grandes universidades - especialmente nos Estados Unidos da América e no Reino Unido. Os resultados científicos e os artigos de pesquisa internacionais são publicados majoritariamente em inglês. A maior parte das universidades no Mundo são, principalmente, formadas por instituiçôes de ensino - nos países em desenvolvimento praticamente todas estão nessa categoria - que devem, por sua parte, adquirir essas publicaçóes para obterem novos conhecimentos.

O Processo de Bolonha também fortaleceu a atratividade estudantes para Reino Unido, isto é, a formação do EEES possibilitou uma maior mobilidade de estudantes estrangeiros para a Inglaterra, principalmente os estudantes europeus continentais; cujas matrículas, a partir das reformas ensejadas pelo Dearing Report, passaram a ser regiamente cobradas. Desta maneira, como efeito desse fluxo de estudantes para IES não gratuitas, ocorreu a formação de um mercado de educação superior na Inglaterra, conforme era previsível desde a publicação do Dearing Report.

A institucionalização da cobrança de anuidades nas universidades inglesas, motivada pelo Dearing Report, possivelmente, seja a mais contundente mudança na educação superior inglesa [com rebatimentos nos campos de educaçáo superior de outros países e no próprio processo de regionalização e de integração da educação superior na Europa pelo Processo de Bolonha] (SHATTOCK, 2006; AZEVEDO, 2008). 
Portanto, duas décadas após a publicação de Dearing Report, o cenário de mercadorização da educação superior, praticamente, está consolidado. A frequência de estudantes internacionais passam a representar um importante mercado de exportação para o Reino Unido. Para ilustrar, vale observar os resultados de estudos do Comitê Assessor de Imigração do Unido que estima, com base em estudo do Department for Education, que, em 2015, houve um faturamento total de 17,6 bilhôes de Libras Esterlinas em serviços educacionais para estudantes estrangeiros em educação superior, ensino básico, aprendizagem de língua inglesa etc. (MIGRATION ADVISORY COMMITTEE, 2018, p.3), significando em moeda brasileira, convertida pela taxa de julho de 2019 , mais de $\mathrm{R} \$ 88$ bilhóes. Neste mesmo documento, os autores do relatório reconhecem que as taxas pagas, principalmente, pelos estudantes originários de países náo europeus é uma forma de subsídio para a educação britânica. O relatório observa que "os estudantes internacionais de fora do EEE [Espaço Econômico Europeu] tendem a pagar taxas mais elevadas para estudar do que os estudantes nacionais. Isso subsidia a educação de estudantes domésticos" (MIGRATION ADVISORY COMMITTEE, 2018, p. 3) ${ }^{11}$. Somente na educação superior, em 2016, estavam matriculados cerca de 450 mil estudantes estrangeiros, enquanto em 1998 eram em torno de 200 mil.

Os estudantes não-europeus, em taxas, pagaram $£ 4,5$ bilhões de Libras, próximo de $\mathrm{R} \$ 22,5$ bilhôes de Reais, para o ano acadêmico 2015/2016, sem contar as despesas de subsistência (alimentação, moradia, lazer, cultura, materiais de estudos e visitas de parentes e amigos) (MIGRATION ADVISORY COMMITTEE, 2018, p. 60). O Departamento de Educação, em relatório intitulado $U K$ revenue from education related exports and transnational education activity in 2016, calcula que, de um total de $£ 19,9$ bilhóes de Libras (próximo de $\mathrm{R} \$ 100$ bilhóes de Reais), a educação superior, durante o ano de 2016, respondeu por $2 / 3$ de toda receita das exportaçôes com educação transnacional (TNE) ${ }^{12}$. Segundo o referido relatório, "o ensino superior é responsável pela maior parcela da receita proveniente de exportaçôes relacionadas à educação e às atividades de Educação Transnacional (TNE). As IES contribuíram com $£ 13,4$ bilhóes de Libras (67\%) do valor total” (DEPARTMENT FOR EDUCATION, 2019, p. 1) $)^{13}$. A figura 1, a seguir, mostra as receitas do Reino Unido com exportaçóes de educação durante o ano de 2016. 


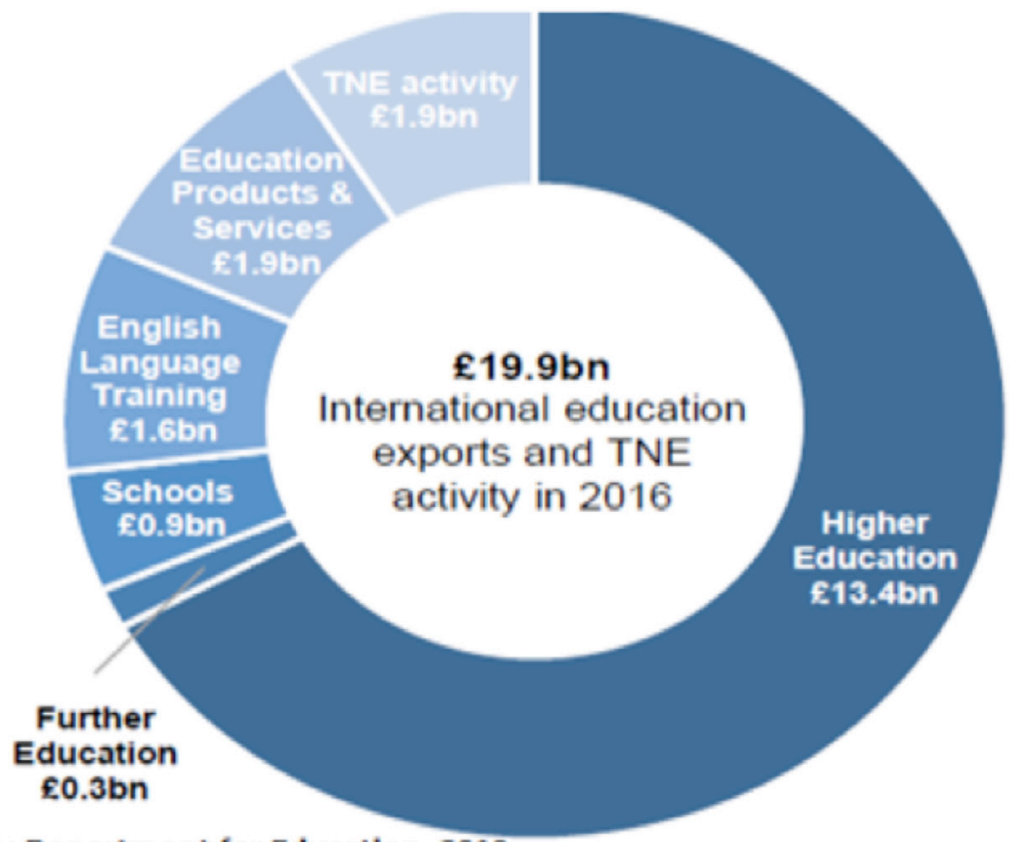

Fonte: Department for Education, 2019

Figura 1: Receita do Reino Unido com exportaçóes de educaçáo (TNE) durante o ano de 2016

Fonte: Department for Education, 2019.

O exemplo no Reino Unido demonstra, tipicamente, que a educação superior vem sendo tratada como uma mercadoria naquele País e como uma fonte de receitas para a permanência de estudantes nacionais e mesmo para a produção do conhecimento e da ciência no Reino Unido. No entanto, a polêmica decisão em referendo, em 23 de junho de 2016, de saída do Reino Unido da União Europeia, que vem sendo chamado de Brexit ${ }^{14}$, além de gerar crise na União Europeia cria impasses para as universidades inglesas que já estavam integradas ao Processo de Bolonha, ao EEES e ao programa de mobilidade Erasmus +. Apesar do Brexit, entretanto, conforme registra Universities UK International (2019), houve um aumento de $2,5 \%$ de estudantes europeus nas universidades do Reino Unido no ano acadêmico de 2017-2018, porém com uma diminuição de 1,5\% dos qua- 
dros científicos (docentes e técnicos). No final de 2018, havia 57.765 trabalhadores (docentes e técnicos) e 157.935 estudantes europeus no Reino Unido (UNIVERSITIES UK INTERNATIONAL, 2019, p. 38).

Como mencionado anteriormente, a educação transnacional é considerada um dos mais importantes itens de exportaçáo do Reino Unido. Em números exatos, segundo registra Universities UK International, com base em dados da Higher Education Statistics Agency (HESA), em 2017-18, estavam matriculados 458.490 estudantes estrangeiros em universidades do Reino Unido, representando 19.6\% do total. Estes representam 14\% dos graduandos e 35,8\% são pós-graduandos (mestrado e doutorado) do conjunto de universidades do Reino Unido. Isto é, na pós-graduação, há um estrangeiro em cada grupo de três estudantes no Reino Unido. A mesma agência contabiliza que uma pessoa em cada conjunto de cinco técnicos e docentes, no Reino Unido, é estrangeira, significando uma proporção de $20 \%$ do staff das universidades (UNIVERSITIES UK INTERNATIONAL, 2019, p. 3). Por fim, vale notar que, proporcionalmente, há pouca presença brasileira na educação superior do Reino Unido. No ano acadêmico 2017-2018, estavam matriculados 1.670 estudantes e registrados 610 trabalhadores acadêmicos (técnicos e docentes) em universidades do Reino Unido (UNIVERSITIES UK INTERNATIONAL, 2019, p. 44).

\section{A mercadorizaçáo da educaçáo superior no Brasil}

No Brasil, existe uma dualidade, pois a educação superior privada representa 3/4 das matrículas e a educação superior pública e gratuita somente 1/4. Assim, dos 8.290.911 estudantes de graduação, 6.241.307 estão matriculados em IES privadas $(75,3 \%)$. Estas grandezas são proporcionalmente opostas na pós-graduação stricto sensu. De um total de 361.530 mestrandos e doutorandos, $304.146(84,1 \%)$ fazem pesquisas em Programas de Pós-Graduação (mestrados e doutorados) em IES públicas no Brasil (BRASIL. MEC-INEP, 2018). As mudanças em curso na legislaçáo da pós-graduação, no sentido de flexibilizar a abertura de cursos/ programas, sobretudo de mestrados e doutorados profissionais à distância, devem levar a uma forte expansão das IES privadas nos próximos anos. 
Desta maneira, a mercadorização da educação superior brasileira, como mencionado, tem sido marcante na graduação, sendo que os variados fundos e empresas transnacionais, proprietários de provedores de educação superior, têm sido beneficiados não somente com o pagamento de taxas escolares diretamente pelos graduandos e suas famílias, mas também por intermédio de bolsas do Programa Universidade para Todos (Prouni) e financiamento por fundos públicos como o Fundo de Financiamento Estudantil (Fies). De acordo com o Jornal Monitor Mercantil, mesmo com a baixa de repasses no primeiro semestre 2018, o Fies transferiu para as IES privadas $\mathrm{R}$ \$ 5,2 bilhôes, de janeiro a junho de 2018, de um total de $\mathrm{R} \$$ 18 bilhóes previstos para o ano de 2018. Sendo que "só as instituiçôes do grupo Kroton Educacional receberam mais de R 1 bilhão neste período" (MONITOR, 2 ago 2018).

Tabela 2: Dez maiores empresas de ensino superior no Brasil, em 2017

\begin{tabular}{c|c|c}
\hline Empresa & $\begin{array}{c}\text { Estimativa de } \\
\text { receita líquida, } \\
\text { em R\$ milhóes }\end{array}$ & $\begin{array}{c}\text { Matrículas } \\
\text { (presencial/ } \\
\text { EAD) }\end{array}$ \\
\hline $\begin{array}{c}\text { Kroton (principais marcas: Anhanguera, } \\
\text { Unopar, Pitágoras) }\end{array}$ & $5.380,36$ & 841.300 \\
\hline Estácio & $3.379,00$ & 441.700 \\
\hline UNIP & $2.418,34$ & 417.400 \\
\hline $\begin{array}{c}\text { Laureate (principais marcas: FMU, } \\
\text { Anhembi Morumbi, UniRitter) }\end{array}$ & $2.534,47$ & 272.200 \\
\hline $\begin{array}{c}\text { Cruzeiro do Sul Educacional (Universidade } \\
\text { Cruzeiro do Sul, Colégio Alto Padrão) }\end{array}$ & 850,80 & 149.800 \\
\hline $\begin{array}{c}\text { Ser Educacional } \\
\text { (Uninassau, Univeritas) }\end{array}$ & $1.231,79$ & 143.400 \\
\hline Uninove & 749,20 & 138.200 \\
\hline $\begin{array}{c}\text { Anima } \\
\text { (São Judas, UniBH) }\end{array}$ & 981,80 & 85.800 \\
\hline UNICESUMAR & 449,50 & 79.500 \\
\hline $\begin{array}{c}\text { Adtalem Global Education } \\
\text { (Damasio, Ibmec, Wyden) }\end{array}$ & 899,51 & 54.600 \\
\hline
\end{tabular}

Fonte: Cunha, 17 Jun 2018, Folha de S. Paulo - com dados da Consultoria Hoper Educação. 
A facilidade de negócios privados com financiamento assegurado pelo tesouro público reafirma a percepção de Florestan Fernandes de que há um "capitalismo sem risco da burguesia brasileira" (FERNANDES, 1972). Por isto, Azevedo (2015), ao analisar o processo de mercadorização da educaçáo no Brasil, referenciado no trabalho de Slaughter e Leslie (1997) sobre o "capitalismo acadêmico", afirma que se trata de "capitalismo acadêmico sem riscos” (AZEVEDO, 2015, p. 91), pois os entes públicos são firmes compradores de vagas no ensino superior pelo Prouni, intermediários e garantidores do Fies e adquirentes de sistemas educacionais (apostilas) para a educação básica, dentre outros produtos e processos educacionais que são adquiridos nos sistemas de ensino públicos. Por isto, como reportou Daniel Silveira para o Portal G1, com base em dados do Instituto Brasileiro de Geografia e Estatísticas (IBGE), houve diminuição de empresas industriais e de outros serviços, porém, "em meio à crise, mercado de educação é o que mais cresce em número de empresas no Brasil” (16 Jun 2019). De acordo com Silveira,

o Brasil encerrou 2017 com pouco mais de 5 milhóes de empresas ativas, 6,73\% menos que em 2013, quando este número superava 5,3 milhóes (...). O maior crescimento no número de empresas nestes quatro anos foi entre aquelas com atividades ligadas à educação, que saltou de 1,3 milhão para quase 1,8 milhão - uma alta de 37,5\% no período (SILVEIRA, 16 Jun 2019).

A transnacionalização da educação superior no Brasil, com a formação de oligopólios, tem início com a entrada de grupos empresariais no mercado de valores mobiliários (bolsa de valores) no ano de 2007. A educação tornou-se um nicho para o mercado financeiro e a atuação dos oligopólios vem crescendo tanto na educação superior como na educação básica. Além disso, empresas e grupos privados também vêm ampliando a atuação por intermédio de venda de sistemas educacionais, gestão de escolas, elaboração e implementação de currículos, formação continuada de professores, disponibilização de plataformas e equipamentos, dentre outros. Ou seja, ao que parece, as parcerias público privadas (PPP) tendem a crescer ainda mais nos próximos anos no Brasil, ampliando a lógica do privado na "educação pública". 


\section{Consideraçóes finais}

Como vimos, a internacionalização e a transnacionalização são temas centrais, especialmente no decorrer do processo de globalização econômica, em discussôes sobre a educação superior, inclusive a pós-graduação, no Brasil, no Reino Unido e em grande parte dos países que favoreceram a abertura da educação como atividade comercial - de mercado. A lógica de expansão e acumulação do capital tem levado os sistemas de educação superior a se metamorfosear no sentido de assumir a perspectiva de mercadorização, tanto na formação (ensino) como na produçáo do conhecimento.

$\mathrm{Na}$ realidade, a modernidade tardia (BAUMAN, 2009) ou a segunda modernidade (BECK, 2009), própria da sociedade de riscos (BECK, 2009), testemunha, não exatamente a internacionalização da educação, que se caracterizaria especialmente pelas interculturalidade e solidariedade, mas, majoritaritariamente, a transnacionalização da educação, que vem sendo facilitada no Brasil, em tempos de globalização e abertura comercial, por programas financiados pelo público e executados por meio de parcerias público-privadas.

A forte expansão da pós-graduação stricto sensu no Brasil nas últimas décadas, assim como a perspectiva de maior participação da oferta por IES privadas, nos próximos anos, em razão da flexibilização de regras regulatórias, coloca para o campo acadêmico o desafio de repensar as bases do SNPG, sua avaliaçáo e seu fomento, assim como o papel dos agentes que regulam, avaliam e supervisionam os cursos/programas, sobretudo CAPES e Conselho Nacional de Educação (CNE). A expansão e a consolidação da pós-graduação stricto sensu no Brasil não estão descuradas da questão da qualidade, tendo por base amplo diálogo com a comunidade científica nas diferentes áreas do conhecimento e entidades científicas representantes das diferentes áreas. As dimensôes e os critérios de qualidade precisam ser discutidos e assegurados para todo o SNPG, garantindo a diversidade dos cursos/programas, em conformidade com as condiçóes objetivas e assimetrias existentes.

A tendência de vincular a qualidade e a excelência aos critérios e métricas de internacionalização, assim como assumir uma perspectiva mais profissionalizante e mercantil na oferta, certamente trará implicaçôes para a natureza e fins da pós-graduação no Brasil. Além disso, a crise econômi- 
ca e os constantes cortes orçamentários na CAPES, CNPq, universidades públicas, institutos de pesquisa, dentre outros, tende a enfraquecer o sistema de avaliação e fomento que perdurou por décadas na institucionalização, expansão e consolidação do SNPG no Brasil.

As dimensóes e os critérios de avaliação vêm sendo adaptados à lógica gerencial de modo a favorecer as regras de mercado e individualizar o credenciamento e avaliação dos cursos/programas. As referências de qualidade construídas nas diferentes áreas de conhecimento/avaliação e que garantem uma especificidade na globalidade e complexidade correm risco de serem substituídas por processos e mecanismos mais flexíveis, cujo fim último, tendencialmente, seriam a mercantilização e a mercadorização da oferta de cursos/programas, especialmente a distância. A pressão [talvez já seja uma tendência] para separar a avaliação dos cursos/programas acadêmicos dos cursos/programas profissionais também tem contribuído na direção de mudar a natureza da pós-graduação e, por consequência, de reduzir as exigências de caráter mais acadêmico-científico.

O SNPG, instituído como política de estado, desde meados dos anos 1960, em um contexto de globalização da economia e do conhecimento, poderia continuar, sem dúvidas, a ser um diferencial estratégico para que o país tenha um projeto de nação e de desenvolvimento mais justo, equilibrado e soberano. Todavia, o que se tem visto avançar é o desmonte da lógica que o constituiu, assim como da qualidade acadêmicocientífica que tem sido uma das suas marcas históricas.

\section{Notas}

1 Disponível em: https://Capes.gov.br/historia-e-missao. Acesso em 01 de ago 2019.

2 Sobre os PNPGs consultar: https://www.Capes.gov.br/plano-nacional-de-pos-graduacao. Acesso em 01 de ago 2019.

3 Sobre a avaliação CAPES: https://www.Capes.gov.br/avaliacao. Acesso em: 01/08/2019.

4 Proposta de Aprimoramento do Modelo de Avaliação da PG. Documento Final da Comissão Nacional de Acompanhamento do PNPG 2011-2020 - 10/10/2018 (CAPES, 2018)

5 O PrInt, criado no governo Temer (2016-2018), substituiu o Programa Ciências Sem Fronteiras, criado no governo Dilma Rousseff (2011-2016), que visava "promover a consolidação, expansão e internacionalização da ciência e tecnologia, da inovação e da competitividade brasileira por meio do intercâmbio e da mobilidade internacional". Previa a utilização de 101 mil bolsas disponibilizadas pela CAPES e pelo Conselho Nacional de Desenvolvimento Científico e Tecnológico (CNPq). Disponível em: http://cienciasemfronteiras.gov.br/web/csf/o-programa. Acesso em 28 de jul 2019. 
$6 \mathrm{O}$ CNPq é vinculado ao Ministério da Ciência, Tecnologia, Inovaçōes e Comunicaçôes (MCTIC) e tem "como principais atribuiçóes fomentar a pesquisa científica e tecnológica e incentivar a formação de pesquisadores brasileiros". Disponível em: http://www.cnpq.br/web/ guest/apresentacao_institucional/. Acesso em 28 jul 2019.

7 Trata-se de volume pequeno de recursos se comparado ao que foi gasto no Programa Ciências sem Fronteiras. "Depois de ter concedido quase 104 mil bolsas no exterior e ter investido R \$ 13,2 bilhôes entre 2011 e 2017, o programa Ciência Sem Fronteiras teve seu fim decretado em abril deste ano pelo Ministério da Educaçâo". Disponível em: http://portal.sbpcnet.org. $\mathrm{br} /$ noticias/o-fim-do-ciencia-sem-fronteiras-depois-de-r-13-bilhoes-investidos-em-bolsas-noexterior/. Acesso em 28 de jul 2019.

8 Apesar da referência ao Reino Unido, em grande medida trata-se de políticas de educaçáo superior da Inglaterra. Para esclarecimento, o Reino Unido da Grā-Bretanha e Irlanda do Norte é constituído por Escócia, Inglaterra, Irlanda do Norte e País de Gales. A Grā-Bretanha abrange Escócia, Inglaterra e País de Gales.

9 Em 1997, o tradicional sistema inglês foi objeto do contundente Dearing Report: Higher Education in the Learning Society, relatório produzido por uma Comissão a pedido do Governo de Margareth Thatcher e aceito pelo Governo de Tony Blair, que deu início a reforma do sistema de educação superior na Inglaterra (AZEVEDO, 2008).

10 Universities UK International, entidade que reúne universidades do Reino Unido, observa que o "Erasmus +, ou Erasmus Plus, é o programa da UE para apoiar a educação, a formaçáo, a juventude e o desporto na Europa. Para o período de 2014 e 2020, há um orçamento de 14,7 mil milhóes de Euros, proporcionando oportunidades para os europeus estudarem, se formarem e ganharem experiência no exterior" (UNIVERSITIES UK INTERNATIONAL, 2019, p. 46). ORIGINAL: "Erasmus+, or Erasmus Plus, is the EU's programme to support education, training, youth and sport in Europe. Running from 2014-2020 and with a budget of $€ 14.7$ billion it provides opportunities for Europeans to study, train, and gain experience abroad" (UNIVERSITIES UK INTERNATIONAL, 2019, p. 46).

11 Original: "International students from outside the EEA tend to pay higher fees for studying than domestic students. This subsidises the education of domestic students". Esta e as seguintes são livres traduçôes dos autores.

12 "TNE - programas educacionais executados 'offshore', seja através de instituições parceiras ou diretamente através de ensino à distância ou campus no exterior". ORIGINAL: "TNE - education programmes delivered 'offshore' either through partner institutions or directly through distance learning or international branch campuses" (DEPARTMENT FOR EDUCATION, 2019, p. 1)

13 ORIGINAL: "Higher Education accounts for the largest share of revenue from education related exports and TNE activity. Higher Education Institutions contributed $£ 13.4$ billion (67\%) of the total value"

14 Brexit is an abbreviation of the two words "Britain" for Great Britain and "Exit" for designating the United Kingdom's exit from the European Union - Brexit é uma abreviação da duas palavras em inglês Britain (Grā-Bretanha) e Exit (saída) para designar a saída do Reino Unido da Uniăo Europeia.

\section{Referências}

ATTALI, J. Pour un modèle européen d'enseignement supérieur. Paris: Stock, 1998.

AZEVEDO, M. L. N. A internacionalização da Educação Superior em questão: mitos, enganos e verdades. Horizontes LatinoAmericanos - Revista de Humanidades e Ciências Sociais do Mercosul Educacional. v. 3, n. 1 (2014), pp. 99-110 
AZEVEDO, M.L.N. Internacionalização da Educação. Entrevista concedida a João Marcos Veiga. Portal da ANPEd. Extraída de http://www.anped.org.br/news/entrevistamario-azevedo-uem-internacionalizacao-da-educacao. Publicada em 27 Julho 2017. Acesso em 11 Julho 2019.

AZEVEDO, M.L.N. Transnacionalização e Mercadorização da Educação Superior: examinando alguns efeitos colaterais do capitalismo acadêmico (sem riscos) no brasil a expansão privado-mercantil. Rev. Inter. Educ. Sup. [RIESup]. Campinas, SP v.1 n.1 p. 86-102 jul./set. 2015.

AZEVEDO, M.L.N. Processo de Bolonha. In: OLIVEIRA, D.A.; DUARTE, A.M.C.; VIEIRA, L.M.F. Dicionário: trabalho, profissão e condição docente. Belo Horizonte: UFMG/Faculdade de Educação, 2010. CDROM.

AZEVEDO, M.L.N. O modelo inglês de educação superior e o Processo de Bolonha; integração, internacionalizaçáo ou mercadorização do espaço europeu de educação superior. In: AZEVEDO, M.L.N. (org.). Políticas públicas e educą̧ão: debates contemporâneos. Maringá: Eduem, 2008.

BAUMAN, Zygmunt. Liquid Times: living in an Age of Uncertainty. Cambridge: Polity, 2009 (reprinted).

BECK, Ulrich. World Risk Society. Cambridge: Polity, 2009 (reprinted).

BRASIL. CAPES. Formação de Professores da Educação Básica. 27 Agosto 2018. Portal da CAPES. Extraído de https://www.Capes.gov.br/pt/educacao-basica. Acesso em 11 Jul 2019.

BRASIL. CAPES. Programa Institucional de Internacionalização - CAPES PrInt. 07 Novembro 2017. Portal da CAPES. Extraído de https://www.Capes. gov.br/pt/cooperacao-internacional/multinacional/programa-institucional-deinternacionalizacao-Capes-print. Acesso em 11 Jul 2019.

BRASIL. CAPES. Proposta de Aprimoramento do Modelo de Avaliação da PG. Documento Final da Comissão Nacional de Acompanhamento do PNPG 2011-2020 10/10/2018. . Brasília: CAPES, 2018.

BRASIL. CAPES. PrInt: instituiçóes selecionadas iniciam execução de projetos de internacionalização. InfoCAPES. Dez. 2018. Brasília: CAPES. Extraído de http://www. Capes.gov.br/infoCapes/002-dezembro-2018/

BRASIL. CAPES. Programa Institucional de Internacionalização - Capes-PrInt, Edital $n^{o}$. 41/2017. Extraído de www.Capes.gov.br

BRASIL. CAPES. Formação de Professores da Educação Básica. Portal da CAPES. 27 Ago 2018. Extraído de https://www.Capes.gov.br/pt/educacao-basica. Acesso em $05 \mathrm{Jul}$ 2019. 
BRITISH COUNCIL. Universidades para o Mundo: desafios e oportunidades para a internacionalização 2018. São Paulo: British Council, 2018. Extraído de www. britishcouncil.org.br

BRITISH COUNCIL. Universidades para o Mundo: estratégias e avanços no caminho da internacionalização 2019. São Paulo: British Council, 2019. Extraído de www. britishcouncil.org.br

CARVALHO, C.H.A. O PROUNI no Governo Lula e o jogo político em torno do acesso ao ensino superior. Educação e Sociedade, Campinas, vol. 27, n. 96 - Especial, p. 979-1000, out. 2006.

CUNHA, Joana. Conglomerados do ensino superior avançam sobre a educação básica. Folha de S. Paulo. 17 Jun 2018. Extraído de https:/www1.folha.uol.com.br/ mercado/2018/06/conglomerados-do-ensino-superior-avancam-sobre-a-educacaobasica.shtml. Acesso em 12 Jul 2019

DEPARTMENT FOR EDUCATION. UK revenue from education related exports and transnational education activity in 2016. London: Department for Education - Higher Education Analysis, 2019.

EUROPEAN HIGHER EDUCATION AREA (EHEA). Ministerial Declarations and Communiqués. Extraído de http://ehea.info/index.php. Acesso em 31 Jul 2019

JORNAL da USP. 10 MITOS sobre a universidade pública no Brasil. Jornal da USP. 28 Jun 2019. Extraído de https://jornal.usp.br/universidade/10-mitos-sobre-auniversidade-publica-no-brasil/. Acesso em 11 Jul 2019

De WIT, Hans. Internationalisation of Higher Education: na introduction on the why, how and what. In: Wit, Hans de (editor). An Introduction to Higher Education Internationalisation. Milan, Italy: Centre for Higher Education Internationalisation (CHEI), Università Cattolica del Sacro Cuore, 2013.

EUROPEAN UNION. Erasmus+ Annual report 2017. European Commission. Bruxelas, 2018.

FERNANDES, Florestan. Democracia e desenvolvimento: a transformação da periferia e o capitalismo monopolista da era atual. São Paulo: Hucitec, 1972.

UNIVERSITIES UK INTERNATIONAL. International Facts and Figures 2019. London: Universities UK International, 2019.

KNIGHT, Jane. Five myths about internationalisation. International Higher Education. Boston College. Center for International Higher Education, issue 67, 23 fev 2011.

McMANUS, Connie. Entrevista. In: BRITISH COUNCIL. Universidades para o Mundo. São Paulo: British Council, 2019.

MEC-INEP. Censo da Educação Superior 2017. Brasília: MEC-INEP, 2018. 
MIGRATION Advisory Committee. Impact of international students in the UK. London: Migration Advisory Committee, September 2018.

MONITOR MERCANTIL. Kroton e Estácio levam R\$ 1,3 bi do Fies. 02 Ago 2018. Monitor Mercantil. Extraído de https://monitordigital.com.br/kroton-e-est-cio-levam-r1-3-bi-do-fies. Acesso em 10 Jul 2019.

OLIVEIRA, João F.; LIMA, D. C. B. P. Pós-graduação e educação à distancia: novos fins, natureza e modus operandi em construção. In: CASTRO, Alda et. al. (orgs). Educação Superior em países e regióes de língua portuguesa: desafios em tempo de crise. 1ed. Lisboa: ED Educa, 2018, v. 1, p. 215-244.

O’MALLEY, Brendan. Education exports worth almost $£ 20$ billion to the UK. University World News. 01 February 2019. Retrieve from: https://www. universityworldnews.com/post.php?story=20190131121139224. Acesso em 16 de ago de 2019.

SHATTOCK, Michael. United Kingdom. In: Forest, James J.F.; Altbach, Philip G. (orgs.). International Handbook of Higher Education: Part One: Global Themes and Contemporary Challenges. Part Two: Regions and Countries. Dordrecht (Netherlands): Springer, 2006

SILVEIRA, Daniel. Em meio à crise, mercado de educação é o que mais cresce em número de empresas no Brasil, diz IBGE. Portal G1. 16 Jun 2019. Extraído de https:// g1.globo.com/economia/noticia/2019/06/26/em-meio-a-crise-mercado-de-educacao-eo-que-mais-cresce-em-numero-de-empresas-no-brasil-diz-ibge.ghtml. Acesso em 17 Jul 2019.

SLAUGHTER, Sheila; LESLIE, Larry L. Academic Capitalism: Politics, Policies, and the Entrepreneurial University. Baltimore: Johns Hopkins University Press, 1997

UNIVERSITIES UK. Patterns and Trends in UK Higher Education 2017. London: UniversitiesUK, 2017. Extraído de www.universitiesuk.ac.uk. Acesso em 16 de ago de 2019.

Recebido em I9 set. 2019 / Aprovado em 2 out. 2019 Para referenciar este texto:

AZEVEDO, M. L. N.; OLIVEIRA, J. F. Internacionalização da educação superior e avaliação da qualidade da pós-graduação: riscos e perspectivas no Brasil e no Reino Unido. EccoS - Revista Científica, São Paulo, n. 51, eI5166, out./dez. 2019. Disponível em: https://doi.org/I0.5585/EccoS.n50.I51660. 